\title{
Biodiesel Production from Castor Oil under Subcritical Methanol Conditions
}

\author{
Nuria Sánchez, José M. Encinar, Gloria Martínez, and Juan F. González
}

\begin{abstract}
Biodiesel is a potentially sustainably renewable fuel for diesel engines; transesterification is the most used method to produce it and high quality vegetable oils are the most usual raw material. Non-edible vegetable oils such as castor oil can provide an alternative feedstock. In this work biodiesel was obtained by transesterification of castor oil with subcritical methanol; the reaction was carried out in an hermetic reactor at temperatures higher than methanol boiling point and with a small amount of potassium methoxide as catalyst. The effect of methanol:oil molar ratios were analyzed, observing that high proportion of alcohol is needed to reach high ester content, the best results were reached with $24: 1$ MeOH:oil molar ratio. Regarding catalyst concentration, 8.7 $\mathrm{mM}(0.12 \mathrm{wt} \%)$ were enough to achieve good results. A temperature of $150^{\circ} \mathrm{C}$ and $1 \mathrm{~h}$ of reaction, at $10 \mathrm{bar}$, were the mildest conditions to reach an ester content higher than $90 \mathrm{wt}$ $\%$. The highest ester content, $94.7 \mathrm{wt} \%$, was achieved at $220{ }^{\circ} \mathrm{C}$, 36 bar and $4 \mathrm{~h}$ of reaction time. Hence good quality biodiesel from castor oil can be produced in subcritical methanol conditions, using a small amount of basic catalyst.
\end{abstract}

Index Terms-Biodiesel, methanol, subcritical, transesterification.

\section{INTRODUCTION}

Biodiesel is a promising diesel fuel substitute because it is a clean renewable fuel which can be used in any direct injection engine without the need to redesign the current technology. Biodiesel is derived from renewable and domestic feedstock and shows higher biodegradability than fossil fuels excellent lubricity and negligible sulfur content [1], [2]. For biodiesel-diesel blends, comparable engine efficiency was showed. From an environmental point of view, in spite of higher emission level of NOx, the emission from biodiesel combustion contained lower amounts of $\mathrm{CO}$, $\mathrm{CO}_{2}, \mathrm{HC}$ and smoke [3].

The most common method to obtain biodiesel is the transesterification of vegetable oils or animal fats. In the reaction, triglycerides are reacted in presence of a catalyst with an alcohol with short-chain [2], [4]. Methanol is the most used alcohol because it is the least expensive alcohol and it shows chemical advantages such as its shorter chain and its polar nature [1], [5]. Conventionally, the catalysts employed for transesterification reaction are homogeneous

Manuscript received March 14, 2014; revised May 14, 2014

N. Sanchez, J. M. Encinar, and G. Martínez are with the Department of Chemical Engineering and Physical Chemistry, University of Extremadura Avda. Elvas s/n, 06006 Badajoz, Spain (e-mail: nuriass@unex.es, jencinar@unex.es, gmarvic@unex.es).

J. F. González is with the Department of Applied Physics, University of Extremadura, Avda. Elvas s/n, 06006 Badajoz, Spain (e-mail: jfelixgg@unex.es). alkaline catalysts such as $\mathrm{NaOH}, \mathrm{KOH}, \mathrm{CH}_{3} \mathrm{ONa}$ and $\mathrm{CH}_{3} \mathrm{OK}$. The most suitable ones are methoxides due to their ability to dissociate into the methoxide and the metal ion without the production of water during transesterification reaction [6].

Biodiesel feedstock can be categorized into three groups: vegetable oils (edible or non-edible oils), animal fats and used waste cooking oil. Biodiesel has been mainly produced from edible vegetable oils all over the world. More than $95 \%$ of global biodiesel production is made from edible vegetable oils and this fact has an influence on the global imbalance to the market demand and the food supply by their high prices and the reduction of food sources. Moreover, it will cause deforestation in some countries [5]. The price of this kind of feedstock makes $70-80 \%$ of the total biodiesel cost. Non-edible oils, which are not used in human nutrition and whose plants could grow in the barren lands, should be increasingly used. Non-edible oil plants usually can be cultivated in lands unsuitable for human crops with much lower cost than the cost for edible oil plants [7].

Castor oil is one of the most often used non-edible oil in biodiesel synthesis [7]. Castor plant is originally a tree or shrub and there are different varieties that can be cultivated. Castor oil seeds usually contain 40 - $55 \%$ oil and the average yield of castor oil seed in the world is about $1.1 \mathrm{t} \cdot \mathrm{ha}^{-1}$, although it may be possible to obtain a maximum of $4.2 \mathrm{t} \cdot \mathrm{ha}^{-1}$. Therefore, castor is amongst the plants with the highest oil yield potential [8].

The conventional method to produce biodiesel is basic-transesterification using a homogeneous catalyst. But this process requires steps of neutralization and washing of the catalyst which increase biodiesel cost [9]. In this process, a large volume of waste water and some saponified components that need to be treated before discharging to the environment or recycling to the process are produced. Moreover, chemicals that are used as catalyst and neutralizers are difficult to recover and the washing step that removes the saponified components in the crude biodiesel is the longest of these steps, since the saponified components interfere with a retard phase separation [10].

Some heterogeneous and lipase catalysts are being developed to fight against these drawbacks, but they have not overcome all of these problems. As much heterogeneous catalyst as lipase catalyst can be more easily separated than homogeneous catalyst but they tend to lose their catalytic activity after several reuse and they have high cost [11]-[14].

Saka and Kusdiana proposed the preparation of biodiesel via non-catalytic method with supercritical alcohol with the aim of overcome these problems [15]. Supercritical fluids are good solvents for many substances when compressed into its state of above the critical temperature and critical pressure. 
These fluids have both gaslike viscosities and liquidlike densities [15], [16]. This process does not require any catalysts or auxiliary chemicals and does not generate significant wastes [10], [15].

Supercritical methanol was used to obtain biodiesel from different oils such as rapeseed, sunflower, soybean and palm kernel [15], [17]-[19]. The highest conversion efficiency was achieved with reaction temperatures between 280 and $400{ }^{\circ} \mathrm{C}$ and pressures between 20 and $45 \mathrm{MPa}$. Meanwhile, methanol critical temperature is $240{ }^{\circ} \mathrm{C}$ and critical pressure 8.09 $\mathrm{MPa}$. Under these conditions the $\mathrm{CH}_{3} \mathrm{OH}$ :oil molar ratios more used were close to $42: 1$ with reaction times around $30 \mathrm{~min}$.

Biodiesel synthesis from castor oil under supercritical ethanol in a catalyst-free continuous process was investigated. The effect of water concentration on the reaction medium, reaction temperature, pressure and substrates flow rate was studied. After the optimization of these variables, the maximum ester content was $74.2 \%$ at $300{ }^{\circ} \mathrm{C}, 20 \mathrm{MPa}$, with a flow rate of $0.8 \mathrm{~mL} \cdot \mathrm{min}^{-1}$ and $5 \mathrm{wt} \%$ water concentration. A favorable effect on ester content was observed when water concentration was increased, unlike the effect of water on the conventional alkaly-catalyzed process [20].

Other authors used methanol and ethanol at subcritical and supercritical conditions to obtain biodiesel from castor oil [21]. The best results were obtained under supercritical conditions and with alcohol:oil molar ratios close to 40:1.

The use of supercritical ethanol or methanol conditions implies high energy expenses and huge cost of the equipments because they have be kept at high temperature and pressure [22]. An alternative method to obtain biodiesel could be the use of methanol at pressure higher than atmospheric but lower than supercritical. By this way, the amount of catalyst would be minimum, therefore the expense in catalyst and neutralizer would be decreased and the waste water flow would be smaller [23].

In this work, the production of biodiesel from castor oil was carried out under subcritical conditions using few amount of catalyst. $\mathrm{CH}_{3} \mathrm{OK}$ was used as catalyst and $\mathrm{MeOH}$ :oil molar ratio, catalyst concentration, reaction temperature and reaction time were studied to know their effect on biodiesel quality.

\section{MATERIALS AND METHODS}

\section{A. Materials}

Refined castor oil, supplied by INTERFAT (Barcelona, Spain), was transesterified using methanol (99.6\%) as alcohol and potassium methoxide $(90 \%)$ as catalyst, they were purchased from Panreac and Alfa Aesar, respectively. Sulphuric acid (95-98\%) to neutralize the catalyst was also purchased from Panreac. The reagents used for oil characterization were of analytical grade. Methyl esters (employed as standards in the chromatographic determination) were purchased from Sigma-Aldrich.

\section{B. Transesterification Reaction}

The reactions were carried out in the system shown in Fig. 1. A cylindrical reactor of $350 \mathrm{~mL}$ made of PTFE. It is located in a vessel of stainless steel and is equipped with magnetic stirring, heating system, sampling outlet, pressure gauge and temperature controller. The reaction vessel was charged with given amounts of oil and a methanol/ $/ \mathrm{CH}_{3} \mathrm{OK}$ solution. Then, the reaction mixture was stirred and heated up to the reaction temperature. The time of reaction was counted when the heating system was switched on. At the end of the reaction a sample was poured out of the reactor and it was neutralized with $\mathrm{H}_{2} \mathrm{SO}_{4}$. Then it was washed with distilled water until glycerol, methanol and the salts of the neutralization were removed. The remaining water was removed by heating at $110^{\circ} \mathrm{C}$.

\section{Analitical Procedure}

Castor oil was characterized by the measure of fatty acid profile, density at $15^{\circ} \mathrm{C}$, viscosity at $40^{\circ} \mathrm{C}$, water content and saponification, iodine and acid value. The used methods were described in previous works [24].

Biodiesel samples were analysed by gas chromatography, VARIAN 3900 gas chromatograph with flame ionization detector was used. The column was a polyethylene glycol column (Zebron ZB-WAX PLUS, Phenomenex, length: 30 $\mathrm{m}$, film thickness: $0.5 \mu \mathrm{m}$ and i.d.: $0.32 \mathrm{~mm}$ ), the carrier gas was helium at a flow rate of $1.4 \mathrm{~mL} \cdot \mathrm{min}^{-1}$, and the analysis was carried out at $220^{\circ} \mathrm{C}$ for $34 \mathrm{~min}$ and at $245^{\circ} \mathrm{C}$ for $29 \mathrm{~min}$ with a ramp of $20{ }^{\circ} \mathrm{C} \cdot \mathrm{min}^{-1}$. Injector and detector temperatures were 270 and $300{ }^{\circ} \mathrm{C}$, respectively. The internal standard method was used with methyl heptadecanoate as standard for minority esters and methyl erucate for methyl ricinoleate. The solvent was ethyl acetate and calibration curves were carried out for all the esters.

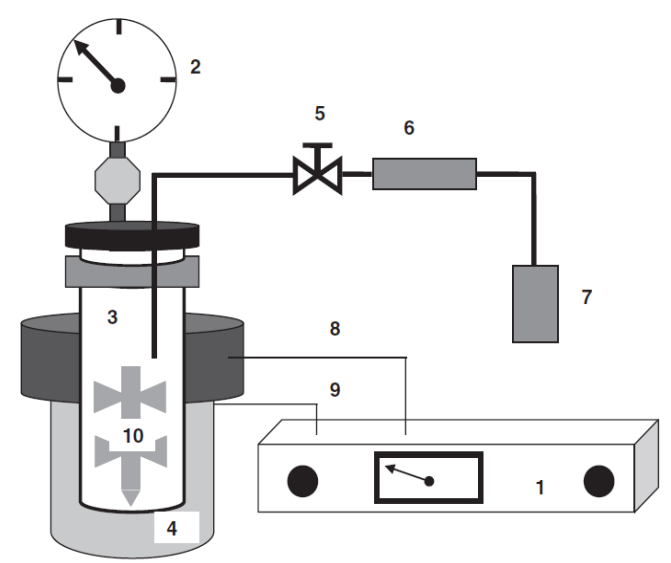

Fig. 1. Subcritical methanol transesterification system. 1: monitor control, 2: pressure monitor, 3: cylindrical vessel made of Teflon, 4:electrical furnace, 5: product exit valve, 6: condenser, 7: collecting sample, 8: agitation rate control, 9: temperature control and 10: magnetic stirrer.

\section{RESULTS AND DISCUSSION}

\section{A. Raw Material}

Raw material properties and its fatty acid profile were shown in Table I. The oil composition of feedstock used in this work is similar to the composition of the castor oil used by other authors [25]. Both have about $90 \%$ ricinoleic acid, $4.5 \%$ linoleic acid and $3.6 \%$ oleic acid. Ricinoleic acid, in which there is a hydroxyl group, shows special chemical and physical properties such as high density and viscosity, high 
hygroscopicity, low iodine value and high solubility in alcohols. The latter property promotes transesterification reaction even at low temperature [8], [26].

TABLE I: CASTOR OIL FATTY ACID PROFILE AND PROPERTIES

\section{Fatty acid profile:}

C16:0 palmitic

$1.3 \%$

C18:0 stearic

$1.2 \%$

C18:1 oleic

$3.6 \%$

C18:2 linoleic

$4.6 \%$

C18:3 linolenic

$0.4 \%$

C18:10H ricinoleic

$88.9 \%$

Density at $15^{\circ} \mathrm{C}$
Viscosity at $40^{\circ} \mathrm{C}$
Water content
Saponification value
Iodine value
Acid value

$$
\begin{gathered}
961 \mathrm{~kg} \cdot \mathrm{m}^{-3} \\
262 \mathrm{cSt} \\
0.31 \% \\
179.3 \mathrm{mg}_{\mathrm{KOH}} \cdot \mathrm{g}^{-1} \\
80.5 \mathrm{~m}_{\mathrm{I} 2} \cdot \mathrm{g}^{-1} \\
1.19 \mathrm{mg}_{\mathrm{KOH}} \cdot \mathrm{g}^{-1}
\end{gathered}
$$

Molecular weight

$926 \mathrm{~g} \cdot \mathrm{mol}^{-1}$

The use of acid or basic catalysis in transesterification reaction depends on the acid value of the raw material. Generally, a value up to $2 \mathrm{mg}_{\mathrm{KOH}} \cdot \mathrm{g}^{-1}$ is suitable to use a basic catalyst [27]. The acid value of the oil used in this work is $1.19 \mathrm{mg}_{\mathrm{KOH}} \cdot \mathrm{g}^{-1}$, therefore potassium methoxide was used as a catalyst in transesterification reaction; as far as basic catalysts are preferable in the case of oils with low acid value [26] and methoxides are more active than hydroxides [6].

B. Effect of MeOH:Oil Molar Ratio on Biodiesel Production

TABLE II: REACTION CONDITIONS AND RESULTS

\begin{tabular}{cccccc}
\hline \hline Run & $\begin{array}{c}\text { MeOH:oil } \\
\text { molar ratio }\end{array}$ & $\begin{array}{c}\text { Catalyst } \\
\text { Concentration } \\
(\mathrm{mM})\end{array}$ & $\begin{array}{c}\text { Temperature } \\
\left({ }^{\circ} \mathrm{C}\right)\end{array}$ & $\begin{array}{c}\text { Time } \\
(\mathrm{min})\end{array}$ & $\begin{array}{c}\text { Ester } \\
\text { Content } \\
(\mathrm{wt} \%)\end{array}$ \\
\hline 1 & $42: 1$ & 8.7 & 220 & 4 & 69.7 \\
2 & $36: 1$ & 8.7 & 220 & 4 & 86.9 \\
3 & $24: 1$ & 8.7 & 220 & 4 & 94.7 \\
4 & $12: 1$ & 8.7 & 220 & 4 & 81.8 \\
5 & $6: 1$ & 8.7 & 220 & 4 & 60.3 \\
6 & $24: 1$ & 10.0 & 220 & 4 & 91.2 \\
7 & $24: 1$ & 5.0 & 220 & 4 & 90.0 \\
8 & $24: 1$ & 1.0 & 220 & 4 & 72.6 \\
9 & $24: 1$ & 8.7 & 190 & 4 & 93.8 \\
10 & $24: 1$ & 8.7 & 150 & 4 & 92.9 \\
11 & $24: 1$ & 8.7 & 170 & 1 & 92.7 \\
12 & $24: 1$ & 8.7 & 150 & 1 & 91.9 \\
13 & $24: 1$ & 8.7 & 100 & 1 & 63.6 \\
\hline \hline
\end{tabular}

In this work were studied the effects of the most important variables in the transesterification of castor oil under subcritical methanol conditions. These variables were $\mathrm{MeOH}$ :oil molar ratio, catalyst concentration, reaction temperature and reaction time. The conditions of the runs carried out were collected in Table II. In this table the ester content reached in each reaction was also shown.

The molar ratio of methanol to oil is a key parameter in the reaction. Biodiesel production could be improved by excess amounts of methanol because it shift the equilibrium to the right-hand side. However, high amounts of alcohol increase the cost of the process. Runs 1 - 5 were carried out to study the effect of $\mathrm{MeOH}$ :oil molar ratio on transesterification reaction. The ester content of the biodiesel produced in each reaction was plotted in Fig. 2.

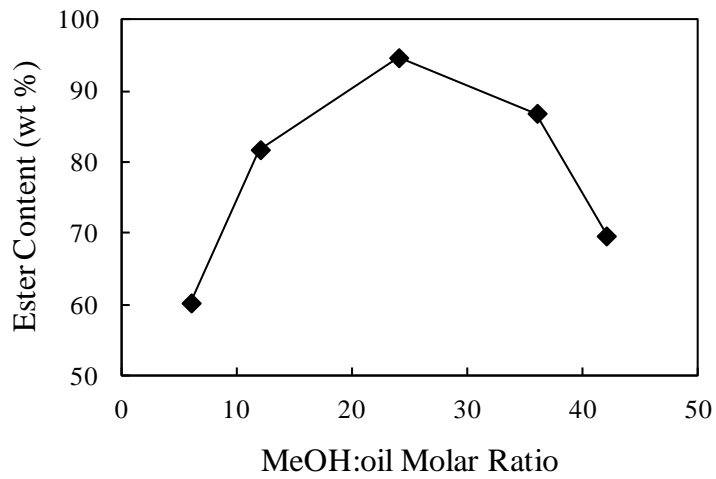

Fig. 2. Influence of $\mathrm{MeOH}$ :oil molar ratio in ester content. Reaction conditions: $8.7 \mathrm{mM} \mathrm{CH}_{3} \mathrm{OK}, 220^{\circ} \mathrm{C}$ and $4 \mathrm{~h}$.

Under the used conditions, increasing the molar ratio of methanol to oil from $6: 1$ to $24: 1$, methyl ester content was increased from $60.3 \%$ to $94.7 \%$. Nevertheless, higher $\mathrm{MeOH}$ :oil ratios led to biodiesel with lower purity. This fact was observed in previous works [28] where rapeseed oil was used.

For noncatalytic reactions in supercritical alcohol, using another type of oil, it was suggested that a higher molar ratio of alcohol is required for better transesterification as excess of alcohol increases the contact area between triglycerides and alcohol. Thus maximum conversions were obtained at molar ratios of 42:1 and 41:1 [29]-[31]. However, castor oil shows high solubility in alcohols, therefore, the contact between triglycerides an alcohol is better.

On the other hand, the presence of high amounts of alcohol complicates the separation between glycerol and biodiesel. Besides, the washing of the biodiesel is more difficult [32]. The decrease of methyl ester content with higher MeOH:oil ratios could be caused by the higher solubility of glycerol in biodiesel and the higher difficulty to wash the biodiesel, it could have some impurities.

\section{Effect of Catalyst Concentration on Biodiesel Production}

The use of supercritical methanol conditions was suggested to avoid the use of catalyst for the reaction of transesterification, because one of the main stages of biodiesel production is its washing [10]. However this technology shows some limitations such us the high energy consumption and the huge cost of the equipments that have to work at high temperature and pressure [22]. To decrease these costs it would be possible to work under subcritical conditions using minimum amounts of catalyst [23].

In this work, low concentrations of $\mathrm{CH}_{3} \mathrm{OK}$ were used as 
catalyst. This catalyst have shown high activity in the transesterification of castor oil [33]. In Fig. 3 was shown the ester content reached when different amount of catalyst were used for the reaction. Concentrations lower than $8.7 \mathrm{mM}$ resulted in an incomplete conversion of the triglycerides into fatty acid esters. These reactions were developed at $220{ }^{\circ} \mathrm{C}$ under methanol vapor pressure with a $\mathrm{MeOH}$ :oil ratio of 24:1. At atmospheric pressure was optimized the ester content and the best conditions were $45^{\circ} \mathrm{C}, 64 \mathrm{mM}$ of $\mathrm{CH}_{3} \mathrm{OK}$ and 18.8:1 as $\mathrm{MeOH}$ :oil molar ratio [33]. Hence more severe temperature and greater concentration of $\mathrm{MeOH}$ allowed a catalyst concentration seven times lower, from 64 $\mathrm{mM}$ to $8.7 \mathrm{mM}$.

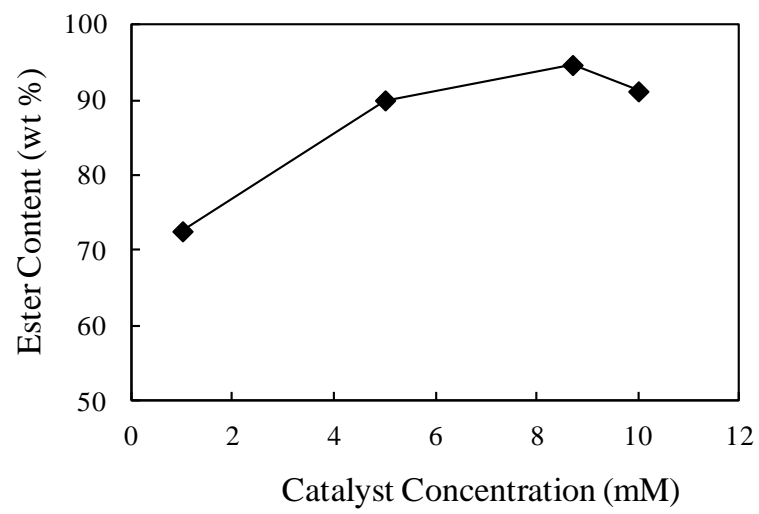

Fig. 3. Influence of catalyst concentration in ester content. Reaction conditions: 24:1 MeOH:oil molar ratio, $220^{\circ} \mathrm{C}$ and $4 \mathrm{~h}$.

Other authors also showed the benefits of working under subcritical methanol conditions such as the required catalyst amount was decreased by $90 \%$ when comparing with the base-catalyzed system at atmospheric pressure [23].

D. Effect of Reaction Temperature and Time on Biodiesel Production

Runs 3, 10 and 11 show the effect of the reaction temperature on the transesterification of castor oil. The ester content reached was plotted in Fig. 4.

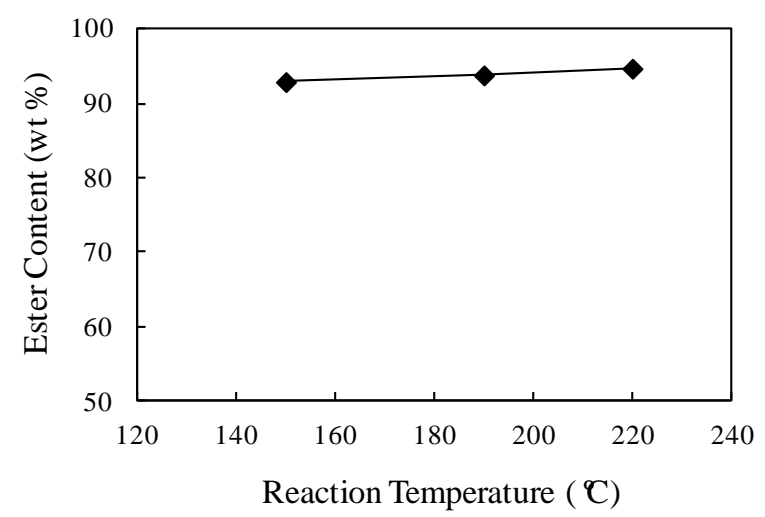

Fig. 4. Influence of reaction temperature in ester content. Reaction conditions: $8.7 \mathrm{mM} \mathrm{CH}_{3} \mathrm{OK}, 24: 1 \mathrm{MeOH}$ :oil molar ratio and $4 \mathrm{~h}$.

The higher temperature, the higher ester content, although there is just a small difference between the percentage of methyl ester for each biodiesel. The increase of $40{ }^{\circ} \mathrm{C}$ of temperature led to the increase of $1 \mathrm{wt} \%$ of methyl ester content.

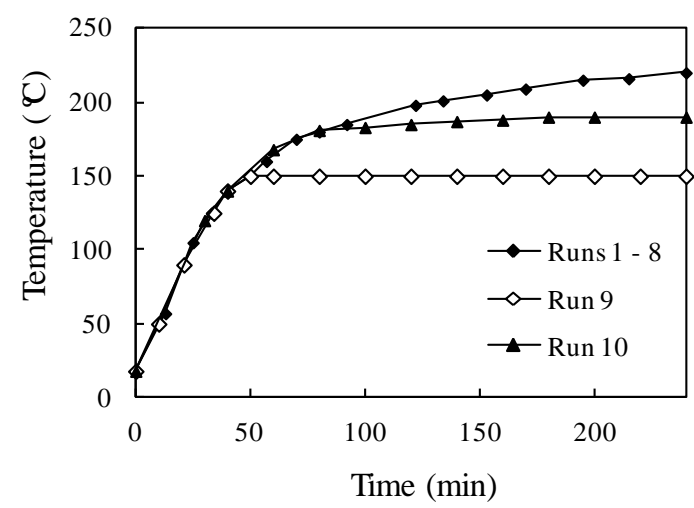

Fig. 5. Temperature profiles.

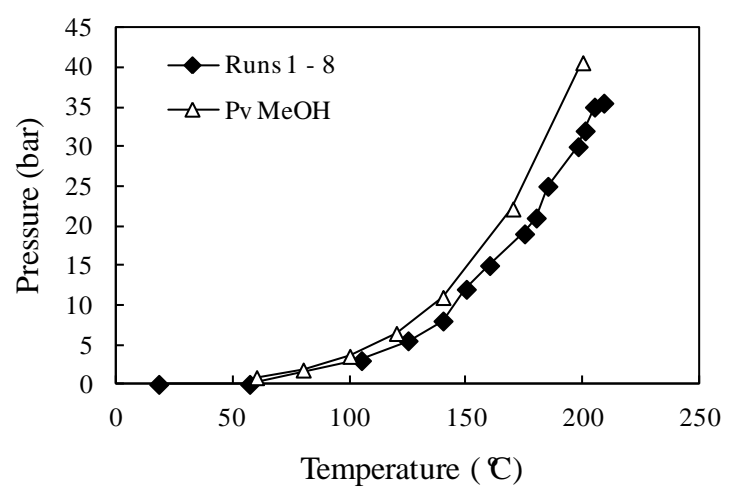

Fig. 6. Pressure vs. temperature for the different runs and vapor pressure of methanol vs. temperature.

The reactions collected in Fig. 4 had a reaction time of 4 hours, although the reaction medium were not at 220,190 or $150{ }^{\circ} \mathrm{C}$ for $4 \mathrm{~h}$. Firstly the reaction temperature was close to $20^{\circ} \mathrm{C}$ because the reaction mixture was settled in the reactor at atmospheric temperature and reaction time was counted from the heating system was switched on. All the reaction followed similar temperature profile, and they are shown in Fig. 5.

As can be seen in Fig. 5, if the reaction time was decreased, $220{ }^{\circ} \mathrm{C}$ could not be reached. Therefore, in the reactions which were carried out with 1 hour of reaction time, 170, 150 and $100{ }^{\circ} \mathrm{C}$ were the programmed temperatures (Runs 11 13, Table II). As it could be expected, the ester content achieved in one hour, was lower than the best result of 94.7 wt $\%$, which was achieved after 4 hours of reaction.

In Fig. 6 the pressure and temperature of the system were drawn to compare with the variation of vapor pressure of methanol when temperature changes. Methanol and castor oil will form an unique solution in the reactor, and its vapor pressure, shown in Fig. 6, was lower than methanol vapor pressure. This fact reminds of Raoult's law for ideal mixtures, because the oil vapor pressure is lower than methanol one, thus mixture vapor pressure was lower than methanol one.

\section{CONCLUSIONS}

In this work the transesterification of castor oil under subcritical conditions was carried out. The effect of the main variables was evaluated and the conditions which led to the maximum ester content were $8.7 \mathrm{mM}$ of $\mathrm{CH}_{3} \mathrm{OK}, 24: 1$ MeOH:oil molar ratio, $220{ }^{\circ} \mathrm{C}$ and $4 \mathrm{~h}$ of reaction. The 
increase of catalyst concentration and $\mathrm{MeOH}$ :oil molar ratio did not improve the final result. However higher temperature could enhance the ester content, although small improvements would be expected with high expenses of energy. The mildest conditions to achieve an ester content higher than $90 \mathrm{wt} \%$ were $150^{\circ} \mathrm{C}$ and $1 \mathrm{~h}$ of reaction, at 10 bar.

In summary, by coupling the base catalysis with subcritical methanol, biodiesel was synthesized from castor oil with a high yield.

\section{ACKNOWLEDGMENT}

The authors would like to thank to the "MICINN" and the "Gobierno de Extremadura" for the financial support received to perform this study by means of Projects ENE2009-13881, PRI09B102, and "ayuda de grupos GR10159" respectively. N. Sánchez thanks the Spanish Ministry of Education for FPU grant received.

\section{REFERENCES}

[1] M. Balat and H. Balat, "Progress in biodiesel processing," Applied Energy, vol. 87, no. 6, pp. 1815-1835, 2010.

[2] G. Knothe, J. Krahl, and J. Van Gerpen, The Biodiesel Handbook, AOCS Champaign IL, 2005.

[3] S. Chattopadhyay and R. Sen, "Fuel properties, engine performance and environmental benefits of biodiesel produced by a green process," Applied Energy, vol. 105, pp. 319-326, 2013.

[4] G. Santori, G. D. Nicola, M. Moglie, and F. Polonara, "A review analyzing the industrial biodiesel production practice starting from vegetable oil refining," Applied Energy, vol. 92, pp. 109-132, 2012.

[5] D. Y. C. Leung, X. Wu, and M. K. H. Leung, "A review on biodiesel production using catalyzed transesterification," Applied Energy, vol. 87, no. 4, pp. 1083-1095, 2010.

[6] I. M. Atadashi, M. K. Aroua, A. R. A. Aziz, and N. M. N. Sulaiman, "The effects of catalysts in biodiesel production: A review," Journal of Industrial and Engineering Chemistry, vol. 19, no. 1, pp. 14-26, 2013.

[7] M. M. Gui, K. T. Lee, and S. Bhatia, "Feasibility of edible oil vs. non-edible oil vs. waste edible oil as biodiesel feedstock," Energy, vol 33, no. 11, pp. 1646-1653, 2008.

[8] V. Scholz and J. N. D. Silva, "Prospects and risks of the use of castor oil as a fuel," Biomass and Bioenergy, vol. 32, no. 2, pp. 95-100, 2008.

[9] G. C. S. Santana, P. F. Martins, N. D. L. da Silva, C. B. Batistella, R. M. Filho, and M. R. W. Maciel, "Simulation and cost estimate for biodiesel production using castor oil," Chemical Engineering Research and Design, vol. 88, issue 5-6, pp. 626-632, May-June 2010.

[10] R. Sawangkeaw, K. Bunyakiat, and S. Ngamprasertsith, "A review of laboratory-scale research on lipid conversion to biodiesel with supercritical methanol (2001-2009)," The Journal of Supercritical Fluids, vol. 55, no. 1, pp. 1-13, 2010.

[11] M. D. Serio, M. Cozzolino, M. Giordano, R. Tesser, P. Patrono, and E. Santacesaria, "From homogeneous to heterogeneous catalysts in biodiesel production," Industrial and Engineering Chemistry Research, vol. 46, no. 20, pp. 6379-6384, 2007.

[12] M. D. Serio, R. Tesser, L. Pengmei, and E. Santacesaria, "Heterogeneous catalysts for biodiesel production," Energy and Fuels, vol. 22, no. 1, pp. 207-217, 2008.

[13] C. Ngamcharussrivichai, W. Wiwatnimit, and S. Wangnoi, "Modified dolomites as catalysts for palm kernel oil transesterification," Journal of Molecular Catalysis A: Chemical, vol. 276, no. 1-2, pp. 24-33, 2007.

[14] Y. Li, D. D. Yu, Y. Wang, and X. L. Guan, "Response surface methodology optimization of lipase-catalyzed transesterification of Jatropha Curcas L. Seed oil for biodiesel production," Biotechnology and Biotechnological Equipment, vol. 27, no. 6, pp. 4284-4289, 2013.

[15] S. Saka and D. Kusdiana, "Biodiesel fuel from rapeseed oil as prepared in supercritical methanol," Fuel, vol. 80, no. 2, pp. 225-231, 2001.

[16] J. Z. Yin, A. Q. Wang, W. Wei, Y. Liu, and W. H. Shi, "Analysis of the operation conditions for supercritical fluid extraction of seed oil," Separation and Purification Technology, vol. 43, no. 2, pp. 163-167, 2005.

[17] G. Madras, C. Kolluru, and R. Kumar, "Synthesis of biodiesel in supercritical fluids," Fuel, vol. 83, pp. 2029-2033, 2004.
[18] H. He, S. Sun, T. Wang, and S. Zhu, "Transesterification kinetics of soybean oil for production of biodiesel in supercritical methanol," JAOCS, Journal of the American Oil Chemists' Society, vol. 84, no. 4, pp. 399-404, 2007.

[19] H. He, T. Wang, and S. Zhu, "Continuous production of biodiesel fuel from vegetable oil using supercritical methanol process," Fuel, vol. 86, no. 3 , pp. 442-447, 2007

[20] I. Vieitez, M. J. Pardo, C. da Silva, C. Bertoldi, F. de Castilhos, J. V. Oliveira, M. A. Grompone, and I. Jachmanián, "Continuous synthesis of castor oil ethyl esters under supercritical ethanol," The Journal of Supercritical Fluids, vol. 56, no. 3, pp. 271-276, 2011.

[21] M. N. Varma and G. Madras, "Synthesis of biodiesel from castor oil and linseed oil in supercritical fluids," Industrial and Engineering Chemistry Research, vol. 46, no. 1, pp. 1-6, 2007.

[22] K. T. Tan and K. T. Lee, "A review on supercritical fluids (SCF) technology in sustainable biodiesel production: Potential and challenges," Renewable and Sustainable Energy Reviews, vol. 15, no. 5, pp. 2452-2456, 2011.

[23] J. Z. Yin, M. Xiao, A. Q. Wang, and Z. L. Xiu, "Synthesis of biodiesel from soybean oil by coupling catalysis with subcritical methanol," Energy Conversion and Management, vol. 49, no. 12, pp. 3512-3516, 2008.

[24] J. M. Encinar, N. Sánchez, G. Martínez, and L. García, "Study of biodiesel production from animal fats with high free fatty acid content," Bioresource Technology, vol. 102, no. 23, pp. 10907-10914, 2011.

[25] J. M. Dias, J. M. Araújo, J. F. Costa, M. C. M. Alvim-Ferraz, and M. F. Almeida, "Biodiesel production from raw castor oil," Energy, vol. 53, pp. 58-66, 2013.

[26] I. B. Banković-Ilić, O. S. Stamenković, and V. B. Veljković, "Biodiesel production from non-edible plant oils," Renewable and Sustainable Energy Reviews, vol. 16, no. 6, pp. 3621-3647, 2012.

[27] M. Canakci and J. Van Gerpen, "Biodiesel production from oils and fats with high free fatty acids," Transactions of the American Society of Agricultural Engineers, vol. 44, no. 6, pp. 1429-1436, 2001.

[28] J. M. Encinar, A. Pardal, and G. Martínez, "Transesterification of rapeseed oil in subcritical methanol conditions," Fuel Processing Technology, vol. 94, no. 1, pp. 40-46, 2012.

[29] D. Kusdiana and S. Saka, "Kinetics of transesterification in rapeseed oil to biodiesel fuel as treated in supercritical methanol," Fuel, vol. 80, no. 5, pp. 693-698, 2001.

[30] P. Krammer and H. Vogel, "Hydrolysis of esters in subcritical and supercritical water," Journal of Supercritical Fluids, vol. 16, no. 3, pp. $189-206,2000$

[31] A. Demirbas, "Biodiesel from vegetable oils via transesterification in supercritical methanol," Energy Conversion and Management, vol. 43 , no. 17, pp. 2349-2356, 2002.

[32] K. Krisnangkura and R. Simamaharnnop, "Continuous transmethylation of palm oil in an organic solvent," Journal of the American Oil Chemists' Society, vol. 69, no. 2, pp. 166-169, 1992.

[33] N. Sánchez, R. Sánchez, J. M. Encinar, J. F. González, and G. Martínez, "A complete analysis of castor oil methanolysis by response surface methodology," Applied Energy, 2014

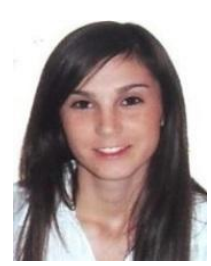

Nuria Sánchez was born on April 5, 1986, in Badajoz, Spain. She received the B.S. degree and M.S. degree from the Science Faculty of Extremadura University, Spain in 2009 and 2010, respectively, all in chemical engineering. She has concluded the realization of her doctoral thesis that will be defended at the end of 2014 Her current research interests include thermochemical processes, energetic use of the biomass residues and obtaining of biodiesel.

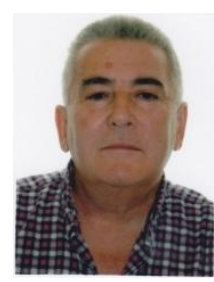

José M. Encinar was born on September 16, 1952, in Cáceres, Spain. He received the B.S. degree from the Science Faculty of Extremadura University, Spain, and the Ph.D. degree from the Extremadura University, in 1977 and 1984, respectively, all in chemical science. Since 1978 he has been with the Extremadura University, where he is currently a professor in the Department of Chemical Engineering and Physical Chemistry. His current research interests include combustion, pyrolysis, gasification, thermochemical processes, energetic use of the biomass residues, active carbons and obtaining of biodiesel and bioethanol. 
Gloria Martínez was born on July 2, 1982, in Miajadas (Cáceres), Spain. She received the B.S. degree and Ph.D. degree from the Science Faculty of Extremadura University, Spain in 2005 and 2012, respectively, all in chemical engineering. Her current research interests include thermochemical processes, energetic use of the biomass residues and obtaining of biodiesel.

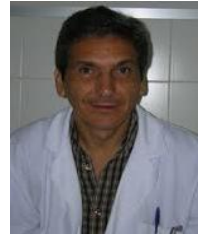

Juan Félix González was born on September 9, 1961, in Badajoz, Spain. He received the B.S. degree from the Science Faculty of Extremadura University, Spain, and the Ph.D. degree from the Extremadura University, in 1985 and 1993, respectively, all in chemical science. Since 1987 he has been with the Extremadura University, where he is currently an assistant professor in the Department of Applied Physics. His current research interests include combustion, pyrolysis, gasification, thermochemical processes, energetic use of the biomass residues, active carbons and obtaining of biodiesel and bioethanol. 



\section{Environmental Pollution Control}


